\title{
DISCUSSÕES SOBRE O ENVELHECIMENTO E A IMAGEM CORPORAL COM MULHERES EM SITUAÇÃO DE VULNERABILIDADE
}

\author{
DISCUSSIONS ON AGING AND BODY IMAGE, WITH WOMEN IN \\ VULNERABILITY SITUATION
}

DOI: http://dx.doi.org/10.5965/1984317815022019102

Mara Evanisa Weinreb

Universidade Feevale maraew@gmail.com

Fernanda Araújo Vidal

fernanda_vidal@hotmail.com

\begin{abstract}
RESUMO
Este é um relato sobre a realização das atividades da Oficina de criatividade desenvolvidas durante o ano de 2016/2017, integrando projeto de Extensão: Laços de Vida - bem-estar de mulheres em situação de vulnerabilidade, da Universidade Feevale. O Presente projeto que atuando no município de Ivoti/RS no Centro de Referência da Mulher (CRM), atendeu aproximadamente 25 mulheres com faixa etária em sua maioria acima dos 60 anos, em um total de aproximadamente 64 encontros.A Oficina de criatividades e propôs a desenvolver uma linguagem expressiva, utilizando recursos artísticos como mediação de suas questões de vida. Essas Oficinas foram coordenadas por uma professora da Universidade Feevale, uma aluna bolsista e uma aluna voluntária. Depois das reflexões sobre os temas surgidos ao longo da realização da Oficina, foi percebida a recorrência do tema envelhecimento em seus diversos aspectos. O Presente artigo, portanto, buscou investigar o processo de envelhecimento vivido pelas mulheres atendidas, revelando a complexidade das transformações corporais que ocorrem durante o envelhecimento e suas consequências emocionais e sociais.
\end{abstract}

Palavras chaves: Extensão. Vulnerabilidade. Velhice. Mulheres.

\section{ABSTRACT}

This is an account of the activities of the Creativity Workshop developed during the year 2016/2017, integrating the Extension Project: Ties of Life - Welfare of Vulnerable Women, from Feevale University. The present project that operates in the municipality of Ivoti / RS in the Reference Center for Women (CRM), and attended approximately 25 women with age group mostly over 60 years, in a total of approximately 64 meetings. The Creativity Workshop set out to develop expressive language, utilizing artistic resources as mediation of its life issues. These Workshops were coordinated by a professor at the Feevale University, a fellow student and a volunteer student. After reflections on the themes that emerged during the workshop, the recurrence of the theme of aging in its various aspects was perceived. The present article therefore sought to investigate the aging process experienced by the women served, revealing the complexity of the corporal transformations that occur during aging and its emotional and social consequences

Keywords: Extension. Vulnerability. Old age. Women. 


\section{INTRODUÇÃO}

O projeto Laços de Vida - bem-estar de mulheres em situação de vulnerabilidade atua desde $2014 \mathrm{em}$ Ivoti, atendendo a mulheres, da fase adulta até o processo de envelhecimento. São mulheres que se encontram em vulnerabilidade psíquica e socioeconômica moradoras de bairros que, segundo dados do Centro de Referência de Assistência Social (CRAS) de Ivoti, apresentam altos índices de famílias chefiadas por mulheres, de baixa escolaridade e de pouca mão-de-obra qualificada. Tendo como objetivo promover a melhora da condição psíquica e a construção de autonomia, são trabalhados temas como autoestima, sexualidade, estereótipos de gênero e violência. Isto porque se entende a importância de ampliar a compreensão das pacientes acerca desses conceitos que recorrentemente são fatores determinantes ao seu bem-estar. Em função disto, junto ao Grupo terapêutico, a Oficina de criatividade veio com o objetivo de atender também às demandas dessa população. $A$ equipe foi formada pela líder do projeto, Ronalisa Torman,

professora do curso de Psicologia;pela professora colaboradora Mara E. Weinreb, professora do curso de Artes Visuais; duas bolsistas, e mais duas voluntárias, ambas dos cursos de Psicologia e Artes Visuais.

A atenção à saúde da mulher desde a fase adulta até seu processo de envelhecimento tem sido um desafio para as ações e políticas voltadas para esse público, pois abarca uma gama interdisciplinar de conhecimentos. Neste sentido, o presente projeto tem como objetivo promover a melhoria do bem-estar, da qualidade de vida e a autonomia no âmbito das variáveis psicológicas e sociais, e o presente projeto promove ações preventivas de atenção à saúde mental e da expressividade humana através de Oficinas em Saúde Mental, Criatividade e palestras.

A violência contra as mulheres tem sido discutida em pesquisas sobre gênero, apontando as dificuldades de modificar a cultura brasileira. As repercussões da Lei Maria da Penha demonstram a dificuldade de lidar com estratégias que apoiem este 
grupo e no caso das mulheres idosas em processo de envelhecimento, a Política Nacional de Saúde da Pessoa Idosa aponta para a necessidade da "[...] recuperação, manutenção e promoção da autonomia e da independência da pessoa idosa [...]". (BRASIL, 2006, p.23), mas que muitas vezes apresentam dificuldades quando colocadas em prática. Assim sendo, voltamos às estratégias que atendessem esse público com Oficinas de criatividade.

\subsection{Conceituando a Arteterapia}

As relações entre as emoções e a criatividade podem ser exploradas por diversos meios de expressão artística, para uma finalidade terapêutica. Segundo o autor Liomar Quinto de Andrade:

A arte é uma forma de expressão do ser humano e como tal, uma forma de comunicação e de linguagem simbólica, é um produto da intuição e da observação, do inconsciente e do consciente, da emoção e do conhecimento, do talento e da técnica, da criatividade. Acolher e utilizar as modalidades de expressões artísticas dentro de um processo psicoterápico, em enriquecer a possibilidade de um conhecimento profundo e consequentemente uma maior compreensão da pessoa a ser auxiliada. (ANDRADE, 2000, p.11).

Esse método pode ser aplicado tanto por profissionais graduados na área da saúde, como psicólogos, enfermeiros e fisioterapeutas, quanto por profissionais da área das artes e da educação, contanto que esses últimos atuem com enfoque interdisciplinar. Para fins terapêuticos, as linguagens a serem utilizadas podem percorrer as técnicas plásticas, as corporais, como a dança e o teatro, a música e a escrita livre. A expressividade do paciente é o mais importante, por meio dela é que o artetereapeuta poderá avaliar o estado clínico do paciente, bem como reabilitá-lo, quando o recurso artístico é a base da comunicação entre o profissional e o paciente, e esta linguagem é o meio de percepção do paciente.

O arteterapeuta "visa criar uma atmosfera suficientemente acolhedora" (ANDRADE, 2000, p. 142), para que o paciente consiga ser envolvido pela 
técnica proposta e se expresse pela cor, pela linha e pelo movimento através do traço. A Arteterapia é um processo terapêutico que utiliza modalidades expressivas diversas, permitindo que o participante expresse através de símbolos seus conflitos e afetos e pode, por isto, ser também um meio de se trabalhar emoções, e resgatar a cidadania e o sentimento de pertencimento.

As atividades artísticas como instrumento de intervenção profissional para a promoção da saúde e qualidade de vida, abrangem, hoje, as mais diversas linguagens: sonora, literária, dramática e corporal, a partir de técnicas artísticas como desenho, pintura, modelagem, música, poesia, dramatização e dança.

Tendo em vista a formação do profissional e o público com o qual trabalha, encontramos diferentes aplicações: na avaliação, prevenção, tratamento e reabilitação voltados à saúde, ou como instrumento pedagógico na educação, como meio para o desenvolvimento (interpessoal através da criatividade em contextos grupais.

O que queremos mostrar aqui é que a arte é um poderoso canal de expressão da subjetividade humana, que permite ao psicólogo e seu cliente, seja ele um indivíduo ou um grupo, acessar conteúdos emocionais e retrabalhá-los através da própria atividade artística. Uma grande diversidade de temas, desde traumas e conflitos emocionais, aspectos das relações interpessoais em um grupo, expectativas profissionais, gênero e sexualidade, identidade pessoal e coletiva, entre outros podem ser abordados pelo psicólogo através da arte.

Trata-se de uma ferramenta que enriquece a tradicional abordagem via linguagem verbal, via conversação, trabalhando aspectos subjetivos através da linguagem artística. A mediação da arte na comunicação apresenta algumas vantagens, entre as quais a expressão mais direta do universo emocional, pois não passa pelo crivo da racionalização que acompanha o discurso verbal. Além disso, com a atividade artística o sujeito entre em contato com suas questões, por um viés criativo, não apenas dando forma a determinado conteúdo subjetivo, mas também podendo configurá-lo em novos sentidos. O modo como esse processo acontece encontra diferentes explicações em função da perspectiva teórica considerada, como será 
analisado adiante, mas a ideia central é esta: Utilizarmos a atividade criadora como um instrumento e um caminho de transformação da subjetividade.

O processo de criação é segundo Salles(2004), sob o ponto de vista do fazer, dentro de um contexto histórico, social e artístico. Um movimento feito de sensações, ações e pensamentos, sofrendo intervenção do consciente e do inconsciente dependendo do arcabouço teórico, podemos conceituar a Arteterapia de diferentes maneiras, mas todas têm em comum a ideia do poder curativo e transformador pela atividade criativa.

Nesse sentido, a Arteterapia é uma forma de terapia que utiliza a expressão artística em todas suas modalidades como instrumento facilitador, com a finalidade de proporcionar um ambiente de liberdade expressiva de forma a permitir que o inconsciente se expresse e revele aquilo que, até então, não era consciente, facilitando o processo terapêutico.

Para Sara Paín (2009), podemos considerar que Arteterapia é uma modalidade na qual a Arte é concebida como uma metáfora, ou seja, como algo que se assemelha à Arte, mas que na qual não há o compromisso com a técnica e a estética, e para a qual se atribui um serviço útil, terapêutico.Por conseguinte, no âmbito da Arteterapia não é a obra artística que interessa, nem a sua qualidade estética, mas sim, o processo criativo, a expressão e a vivência em si e as consequências emocionais advindas desta experiência.

Para obtermos uma melhor compreensão do que constatamos ao longo dos encontros, buscamos estudar os conceitos de velhice, de envelhecimento e de corporeidade.

\subsection{Envelhecimento e corpo}

O aumento da expectativa de vida da população mundial e nacional contribuiu para que o tema do envelhecimento passasse a ter destaque na agenda das políticas públicas, tanto em âmbito internacional como nacional. Assim, algumas. mudanças vão surgindo a partir das novas políticas de atenção à saúde do idoso, que têm por objetivo 
redimensionar o atendimento a este grupo através de programas assistenciais que assegurem direitos e promovam ações inovadoras no sentido da melhoria na qualidade e vida dos idosos. Isto porque os avanços ocorridos na medicina, em especial na Geriatria preventiva e curativa, ainda que venham aumentando a expectativa de vida dos seres humanos, não significam melhoria da qualidade de vida.

O envelhecimento é um processo inevitável do ponto de vista cronológico e biológico. Neste período, as funções fisiológicas tendem a diminuir e a pessoa fica mais propensa ao aparecimento de algumas doenças crônicas consideradas como características da velhice, mas cuja gravidade depende, basicamente, do estilo de vida. O sedentarismo é um exemplo de estilo de vida diretamente relacionado com a qualidade de vida do idoso. Nesta fase da vida, a constatação de mudanças na imagem corporal, do declínio físico e desaparecimento gradativo da juventude, mobiliza ansiedades e provoca questionamentos sobre o sentido e significado de questões da vida

Além das inevitáveis mudanças biológicas, quanto mais velho o indivíduo, maior o número de perdas com as quais terá que conviver. No confronto com estas perdas e limitações, advindas deste processo de envelhecimento - sobretudo em uma sociedade que privilegia os jovens -o idoso torna-se mais vulnerável, com uma percepção distorcida de suas reais possibilidade e com o seu potencial criativo bloqueado, acarretando baixa estima e falta de adaptação, agravadas, estas, pela visão preconceituosa e estereotipada que a sociedade, em geral, tem da velhice. Entretanto, cada pessoa tem um modo peculiar de envelhecer, podendo seguir sua vida de forma ativa e sadia em constante evolução ou perder o prazer de viver e tornar-se extremamente dependente dos outros.

Segundo Balbinotti (2003), o que define uma pessoa como idoso - que ela prefere chamar de adulto maduro - é seu estado de saúde física, psíquica e intelectual. Para esta autora o idoso, ou adulto maduro: 
É um sujeito que sofreu uma série de vivências e transformações tanto físicas quanto psicológicas e afetivas ao longo do tempo vivido e que cumpriu algumas das principais exigências pessoais na fase adulta jovem, como: ter mantido relações com um parceiro, ter optado ou não pela procriação, ter exercido - ou exercer - uma atividade profissional, estabelecer relações de amizade, enfim, ter atendido socialmente às demandas necessárias e que, ao ingressar num segundo momento da vida adulta, se mantenha em evolução.(BALBINOTTI, 2003, p. 25).

Sabemos que o impacto do envelhecimento pode ocasionar no idoso uma alteração em seus hábitos de vida com modificações em suas rotinas diárias e substituição por atividades e formas de ocupação pouco ativas, o que pode determinar a redução no desempenho físico, na habilidade motora, na capacidade de concentração e de coordenação, gerando, consequentemente, um processo de autodesvalorização, insegurança, perda da motivação e depressão. Nesse sentido, os transtornos físicos apresentados no envelhecimento não podem ser enfocados de forma dissociada dos afetos e emoções.

A falta de compreensão das implicações afetivas e psicológicas que envolvem o processo de envelhecimento estigmatiza o idoso e contribui para a formação da ideia preconceituosa de que ser idoso é ser uma pessoa dependente, frágil, senil e velhice, sinônimo de doença e de deterioro cerebral irreversível.Por conseguinte, o problema não é a velhice em si, mas a ideologia dominante na sociedade que envolve o processo de envelhecimento; sociedade esta que elegeu a beleza e a jovialidade como parâmetros e sinônimos de saúde.

A velhice é uma etapa da vida, assim como as demais, diz

Eliane Blessmann (2004), assistente social especializada em Gerontologia Social. Portanto, órgãos como a ONU estabelecem uma idade para o início de cada etapa que seja comum à maior parte das pessoas. Nos países desenvolvidos, a idade estabelecida como o início da velhice é aos 65 anos e nos países em desenvolvimento, é aos 60 anos. No entanto, por mais natural que a velhice seja, há uma construção social que estabelece paradigmas negativos para essa etapa. 
O fisioterapeuta Pedro Paulo Monteiro (2001) especializado em Neurologia e mestre em Gerontologia, diz que a identidade social do velho "[...\} impõe uma norma a ser cumprida, afastando-o do seu convívio social e, consequentemente, minimizando suas oportunidades de aquisição do conhecimento". (MONTEIRO, 2001, p. 23). Segundo o autor, a velhice é encarada como algo triste, pois o corpo velho é visto como uma "máquina" desgastada pelo tempo. As pessoas, portanto, excluem o velho por não desejarem, para si esse papel futuro.

Com a crença de que o velho é frágil e de que a velhice indica a chegada do tão merecido descanso, a sociedade o isola. Isso, somado ao padrão de beleza que rejeita as mudanças físicas ocorridas na velhice, contribui para o pensamento de que o velho não tem mais as necessidades e desejos que possuía e que, portanto, não tem mais a necessidade por aprendizado e por experiências novas. Em consequência desse senso comum, é oferecido ao idoso somente o suprimento das necessidades básicas:

“[...] uma alimentação sem sabor, roupas antigas porque o corpo não oferece mais nenhum tipo de sedução, um lugar para o seu descanso, com espaço reduzido porque não há mais necessidade de expandir seus desejos, mesmo porque o desejo é exclusividade dos jovens." (MONTEIRO, 2001, p. 32).

O fisioterapeuta então menciona Simone de Beauvoir,dizendo que; os velhos manifestam desejos, sentimentos e reivindicações comuns aos jovens, isso é visto como um escândalo. Quando eles apresentam sentimentos de amor e ciúme, é considerado ridículo; quando exercem sua sexualidade, são repudiados; ao demonstrarem violência, é visto como insignificante. Deles, é esperado serenidade e conformação: o idoso é idealizado como aquele que já alcançou o domínio da condição humana, que já apreendeu toda a sabedoria e, portanto, espera-se dele boa conduta e que aja de acordo com todas as virtudes. Se os velhos reclamam a sua condição ou se afastam desse ideal, têm questionada sua sanidade: são "loucos" ou "caducos". As imagens criadas do velho, a do ideal e a imagem degradante, negam-no a humanidade. O velho é julgado por um olhar que não lhe enxerga como ser humano igual, e por isso nega-se a eles uma vida digna. 
Segundo Monteiro (2001), para a Antropologia, a construção das identidades sociais,tem como fator determinante as relações de contraste, isto é:o "eu" é o oposto do "outro". Desse modo, "[...] identidade do velho é construída pela contraposição à identidade do jovem".(MONTEIRO, 2001, p. 46). A identidade social do velho carrega estigmas - fraqueza, incapacidade, dependência - que são o oposto do padrão idealizado da identidade do jovem: força, beleza, capacidade produtiva. Sendo assim, "fica claro porque as pessoas não querem e não aceitam ser classificadas como velhas, dizendo, muitas vezes, que possuem uma alma jovem em corpo de velho" (MONTEIRO, 2001, p. 47).

O tratamento dirigido aos idosos pela sociedade, segundo Blessmann (2004), é diferenciado conforme época e local. Antigamente, o velho era o acumulador do saber, quando não havia livros, ele tinha a função de passar oralmente a tradição e os conhecimentos. Até o século XIX, a velhice tinha valor simbólico socialmente, pois os mais velhos representavam sabedoria e detinham autoridade e acumulação de bens. Com a industrialização, ganha reconhecimento o trabalho produtivo, próprio aos jovens. A ciência e a técnica passam a dominar o mundo na modernidade e os mais jovens são os que as detém. $O$ jovem é valorizado enquanto a identidade social do velho passa a ser de decadência física e fragilidade biopsíquica. À velhice está reservada a ausência de papéis sociais e a perda de status e de poder econômico.

$\mathrm{Na}$ contemporaneidade, pode-se verificar o início de uma revisão dos estereótipos que envolvem a velhice. Com o surgimento do termo Terceira Idade, há uma nova imagem do idoso. A expectativa de vida e as taxas de sobrevida aumentam e com isso aumentam também:

As oportunidades de realização e satisfação do idoso, deixando a velhice de ser caracterizada pelo ócio. [...] impõe-se uma nova ideologia de velhice caracterizada relatividade, participação e responsabilidade pessoal de cada pessoa envelhecer bem.(BLESSMANN, 2004, p.15).

O envelhecimento é um processo vivido por todos os seres humanos, pois a vida em si parte desse processo. As mudanças no organismo ocorridas ao longo da existência de uma pessoa são parte do envelhecer. Apesar de a velhice ter uma idade 
estipulada pela sociedade, o envelhecimento é diferente para cada um e as mudanças podem ser variadas em tempo e aspectos. Monteiro trata do quão natural é o envelhecimento ao escrever:

Quando me refiro à vida, remeto-me diretamente ao processo do envelhecimento, porque envelhecer e viver são processos indissociáveis. Desenvolvemos uma infinita rede de relações por meio de várias histórias que colhemos e tecemos durante todo o percurso de nossas vidas. Estamos desde a concepção, envelhecendo e vivendo, vivendo e envelhecendo, nunca sendo os mesmos, porque envelhecer é um processo contínuo de transformação do ser humano como único em seu tempo vivido (.MONTEIRO, 2001, p.15).

Segundo o autor, assim como o envelhecimento é inerente à vida, o conhecer é inerente ao viver. Portanto, é fundamental para a vida que haja sempre estímulo. Ele ressalta o estímulo sensorial, por serem os sentidos a ponte que leva o ser humano a compreensão do mundo e então, a adaptação do organismo. Devidoà crença que há de que o idoso não necessita de mais experiências nem de estímulo, ele é isolado. 0 próprio idoso pode, eventualmente, internalizar esse pensamento limitante. $O$ isolamento é nocivo ao ele porque, conforme Monteiro, o priva do contato vital com o mundo: "O isolamento reduz a capacidade em adquirir sensações novas e variadas, propiciando a acomodação dos sentidos, deixando esses indivíduos entregues à privação sensorial e à fome afetiva".(MONTEIRO, 2001, p. 31).

Ao se falar sobre envelhecimento se faz necessário conhecer o conceito de corporeidade e sua contribuição, para que se entenda o processo subjetivo do envelhecimento. Similar à forma como a sociedade pensa o velho; o oposto do jovem, o pensamento comum divide a mente do corpo. Essa mentalidade dualista gera uma relação de diferença, onde de um lado está o superior e no outro o inferior. Assim como a velhice é considerada negativa pelas pessoas, o corpo, quando visto como algo à parte da mente, está sujeito a diversos significados estabelecidos. Ele pode ser fraco ou forte, bonito ou feio, jovem ou velho.

Conforme Blessmann (2004), ao longo da história da humanidade, o corpo já foi deixado em segundo plano, atrás da mente e do espírito; foi tido como obsceno e como meio para o pecado; foi entendido como simples materialidade, estando sob o controle 
da mente; teve valor apenas pelo potencial de produção; e atualmente, o corpo é entendido no capitalismo como um objeto. As pessoas se tornam consumidoras e o corpo adquire mais valor, à medida que é vendida a ideia de modificação do corpo em busca do visual ideal vigente.

A perspectiva de divisão e classificação sobre o que é o ser humano, é limitante e sempre diminuiu a importância de um dos aspectos. O termo corporeidade apresenta uma visão unitária. É importante reconhecer a totalidade do ser humano, onde corpo e mente são partes de uma mesma dinâmica.

A corporeidade diz que o corpo todo é inteligente e sente. O corpo, a mente, e os sentimentos não devem ser dissociados. O envelhecimento é vivido no corpo, que é por sua vez o todo do ser humano. Blessmann (2004) reforça o pensamento de Monteiro (2000), sobre a identidade social estigmatizada do velho ao apresentar as visões que existem sobre o corpo em sua pesquisa. Segundo ela, a visão do corpo físico e biológico contribui para a dificuldade de aceitação do envelhecimento. Trata-se de quando o indivíduo se vê velho, porém acredita que há o seu eu invisível que se mantém jovem. A assistente social apresenta também o entendimento do corpo por sua funcionalidade. Sob essa perspectiva, o idoso acredita que o corpo saudável tem mais valor que o corpo belo, já que não apresenta mais o visual idealizado devido às mudanças físicas de envelhecimento.

\section{METODOLOGIA}

As mulheres em situação de vulnerabilidade são encaminhadas ao projeto após acessarem o CRAS, o Centro de Atenção Psicossocial (CAPS) ou próprio Centro de Referência da Mulher. As psicólogas docentes da Universidade Feevale realizaram, por meio de uma conversa com cada uma delas, uma triagem onde foi aplicado um questionário para verificar se a paciente se adequa aos grupos oferecidos pelo projeto.

Desde 2016, a Oficina de Criatividade foi incorporada ao Projeto, concomitantemente ao Grupo Terapêutico, já desenvolvido alí, com espaço nas 
funcionalidades do projeto. No decorrer deste ano, atendemos, em um total de 24 encontros, aproximadamente 25 mulheres, por vez, sendo sete o número médio de mulheres que estiveram presentes entre 10 a 15 encontros. As beneficiárias encontravam-se semanalmente nas quintas feiras, no turno da tarde, em um espaço cedido pelo CRM com a psicóloga, docente da Universidade Feevale e suas alunas, uma voluntária e uma bolsista. O local cedido é composto por uma sala ampla, acomodando até 20 pessoas, duas mesas grandes e cadeiras. Cerca de metade das mulheres atendidas já frequentavam o CRM, que oferece atividades como; bingo, aulas de artesanato, e massagem.

$\mathrm{Na}$ Oficina de criatividade proposta pelo Projeto Laços de Vida, o recurso utilizado em todos os encontros ocorridos, em 2016, foi o das Artes visuais. Predominaram as propostas de desenho, pintura, pintura abstrata e colagem. Utilizaram-se lápis de cor, canetas hidrocor, gizes de cera, tintas guache, pincéis, cola branca escolar, tesouras, folhas para desenho de tamanho A3 e papel pardo. As participantes, em um primeiro momento, foram introduzidas a proposta das atividades, pela psicóloga que coordenava o grupo. Foi explicado às participantes que durante a execução dos trabalhos não devia haver uma preocupação com o resultado final; o mais importante era a possibilidade de conseguirem se expressar melhor através desta linguagem não verbal. Desse modo, elas foram tranquilizadas frente a um sentimento de hesitação, e não haveria expectativas quanto à estética e quanto ao uso da técnica, durante a realização das criações. Esse momento de recepção e explicação que ocorreu no primeiro encontro foi repetido sempre que chegava ao grupo uma nova participante. Em seguida, a proposta da atividade foi apresentada às mulheres, que sempre se utilizou do recurso simbólico. Quando Notadas dúvidas por parte das participantes, por meio de exemplificações introduziu-se uma gama de possibilidades, para que encontrassem um meio de iniciarem suas criações.

As alunas extensionista redigiram os encontros, e colaboraram para uma atmosfera de acolhimento, participamos das atividades desenvolvidas, e inclusive contribuindo na programação das mesmas, sempre que necessário. Foi essencial esta 
contribuição, para que as mulheres se sentissem confortáveis no decorrer da Oficina, quando houvesse dificuldades no manuseio dos materiais, como diante de alguma barreira criativa que pudesse surgir. Passado o momento de produção, era feita a conversa a respeito do tema proposto. Cada participante falava sobre como se sentia em relação ao seu trabalho. Esse momento era também muito importante, pois oportuniza o entendimento de suas produções e uma troca de seus relatos de vida. As participantes podiam identificar-se umas com as outras e apoiarem-se mutuamente, demonstrando empatia através de suas falas e vontade de superarem suas dificuldades e seu estado emocional.

Por meio de reuniões semanais ocorridas no local do CRM (Centro de Referência da Mulher),com as professoras do Projeto, em horário que antecede aos encontros da Oficina, e a participação nas palestras promovidas, no intuito de informar as mulheres sobre Direitos humanos e atenção à saúde física e mental,foi possível a troca de impressões entre as alunas extensionistas, sobre os relatos e o bem-estar apresentados pelas participantes. A partir disso, constataram-se temáticas recorrentes sobre as quais foi feita uma pesquisa teórica que resultou no aumento da compreensão acercas das participantes atendidas. Os relatos das mulheres, bem como as atividades eram transcritos para nosso diário de campo, depois quantificados e separados por temáticas, salvando os nomes delas, para a melhor leitura dos casos individuais. Em um total de 24 encontros, foi constatado que 13 deles apresentaram relatos de questões sobre o envelhecimento, dentre as 25 mulheres que vivenciaram a Oficina de criatividade. Em uma análise mais aprofundada, oito mulheres em oito relatos apresentaram uma nova visão do idoso, e conforme Blessmann (2004) constatou, é a terceira Idade ativa, representada pela responsabilidade pessoal de se envelhecer bem, com saúde e boa autoestima. 


\section{RESULTADOS PARCIAIS}

Quanto aos resultados parciais, trouxemos nove depoimentos das mulheres, e duas imagens de colagens confeccionados por elas, particularmente a partir do quinto encontro, quando começaram a trazer em suas falas, uma desconstrução do padrão de envelhecimento, começando com a participante IV. que disse o seguinte:

"[...]quando casamos, era só trabalho. A Terceira Idade é a melhor!".

Nessa fala, entende-se que a participante vê na idade em que se encontra uma possibilidade diferente de sua vida quando jovem-adulta, período esse em que passou muito trabalho. Agora, ela tem tempo para o lazer.

Nesse mesmo encontro, a participante mais velha do grupo, de 69 anos, A. expressou surpresa dizendo ter observado:

\section{"[...] va vitalidade dos idosos de hoje!".}

Em seguida, a participante M.J., comentou sobre ter visto um senhor quesegundo ela, aparentava ter em torno de 90 anos, dançando em um baile, muito e animado.

"Se eu fosse viver até os 90 ! Aquela vontade de viver!".

No relato de A., é interessante como ela fala na terceira pessoa a respeito do grupo etário em que se encontra. Ao mesmo tempo, é evidenciada a ideia de que a identidade social do idoso está sendo revista, tendo em vista que a participante diferencia os idosos de hoje daqueles daantiga visão de velhice ociosa, que era o esperado. A fala de M.J. reforça a ideia da vitalidade dos idosos e também apresenta a si mesma distante dessa realidade.

No referido encontro, a proposta foi que as participantes, desenhassem juntas, uma árvore em papel pardo e a preenchessem com imagens recortadas de revistas 


\section{EDUCAÇÃO, \\ ARTE'S E INCLUSÃO}

(Figura 1). Foi-lhes dito que uma árvore tem suas raízes, o tronco que a sustenta e os frutos que gera. A participante N. fez a seguinte explicação sobre sua participação no trabalho:

"Família que começa tem que ter amor e carinho. Alimentação, ginástica, rezar - pra crescer. Autoestima pra cima, se não, tem depressão".

Conforme citou N., a família representa as raízes. O tronco da árvore adquiriu a representação do corpo e do espírito: o espírito que se apoia na fé, o corpo que deve ser bem alimentado, ressaltando a importância da prática de exercício físico para crescer. Não foi só em relação à saúde física que essa consideração foi feita, mas como o exercício e a atividade física têm a oferecer para o bem-estar e para a saúde mental. A participante M. expressou:

"Se eu não vou à academia, me faz uma falta".

Esses relatos estão de acordo com a fala de Blessmann (2004), a respeito da nova imagem do idoso - que tem participação social, é ativo e se preocupa em envelhecer bem. No encontro realizado em dois de agosto de 2016, quando a proposta do Nome foi repetida para averiguar uma possível melhora a nível emocional das mulheres, a participante $\mathrm{C}$. fez em sua inicial a representação de uma borboleta e disse:

\section{"[...]porque gosto de voar por aí!”.}

Após, contou uma história longa e animada do que fez em suas viagens de inverno. 


\section{EDUCAÇÃO,}

ARTES E INCLUSÃO

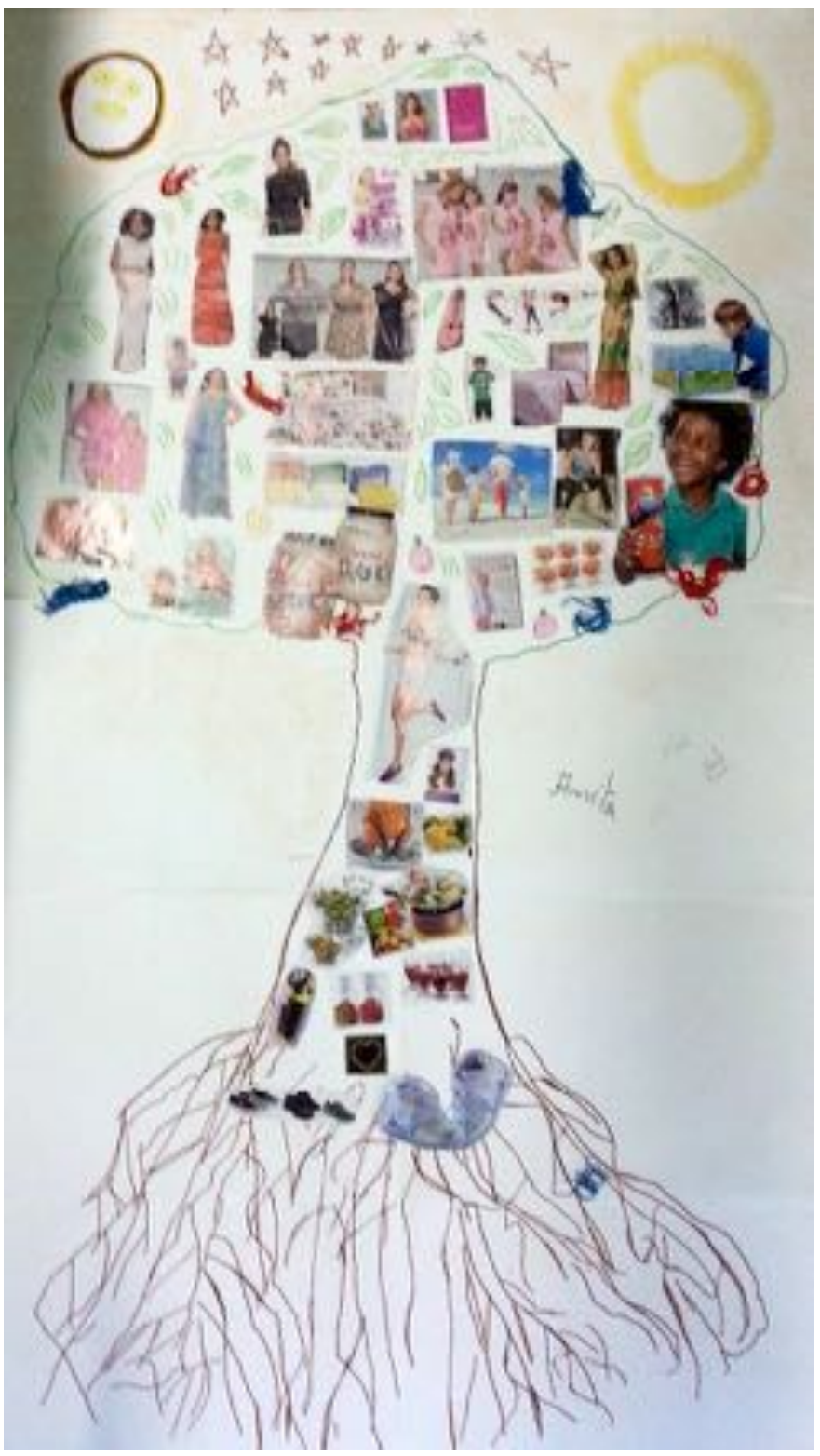

Figura 1. A árvore da vida.Colagem.. 2016. Acervo da autora

Pode-se verificar a confirmação dos estigmas da identidade social do velho, de acordo com Monteiro (2004), na fala de quatro participantes. Em dois relatos, há demonstração de identificação com determinadas situações as quais o idoso é, muitas vezes, condicionado a estar ou a se sentir parte delas. Um desses relatos ocorreu no sexto encontro, quando estava proposto às pacientes que pensassem no crescimento 
de uma flor e em suas etapas e, a partir disso, realizassem um desenho individual. A participante J. falou sobre seu trabalho:

"Me desenhei aqui. (...) a gente fica murcha. A idade chega e tudo demora mais".

O relato de J. é semelhante à ideia de declínio, enquanto o segundo relato traz o pensamento da dependência do idoso - A., ao falar do sofrimento que as mães passam para ter seus filhos, diz sobre sua filha:

\section{"[...]é ela que cuida de mim hoje".}

Fica, no entanto, ainda mais evidente a situação do idoso que adota a visão estigmatizada do velho e não se sente adequado a esse condicionamento. A participante N. no encontro do dia quatro de outubro de 2016, quando ao final do trabalho lhe foi pedido que desse um conselho ou uma mensagem positiva a si mesma, disse a seguinte frase:

"Não pode achar que se é idoso".

No dia treze de setembro, as mulheres trabalharam com uma proposta de colagem em conjunto, onde elas deveriam criar um painel com o título: A Mulher que se supera. Elas colaram imagens de mulheres jovens, de pessoas praticando exercício físico, de animais de estimação, de comida, de meios de transporte, de cosméticos e acessórios e uma imagem com o dizer; sexo é vida. Todas juntas traçaram o perfil dessa mulher (Figura 2). Escolheram chamá-la de Lady e atribuíram-lhe 34 anos de idade e 1,60 cm de altura. Uma das participantes escreveu ao final a descrição da vida de Lady que as participantes construíram em conjunto: 


\section{EDUCAÇÃO, ARTES E INCLUSÃO}

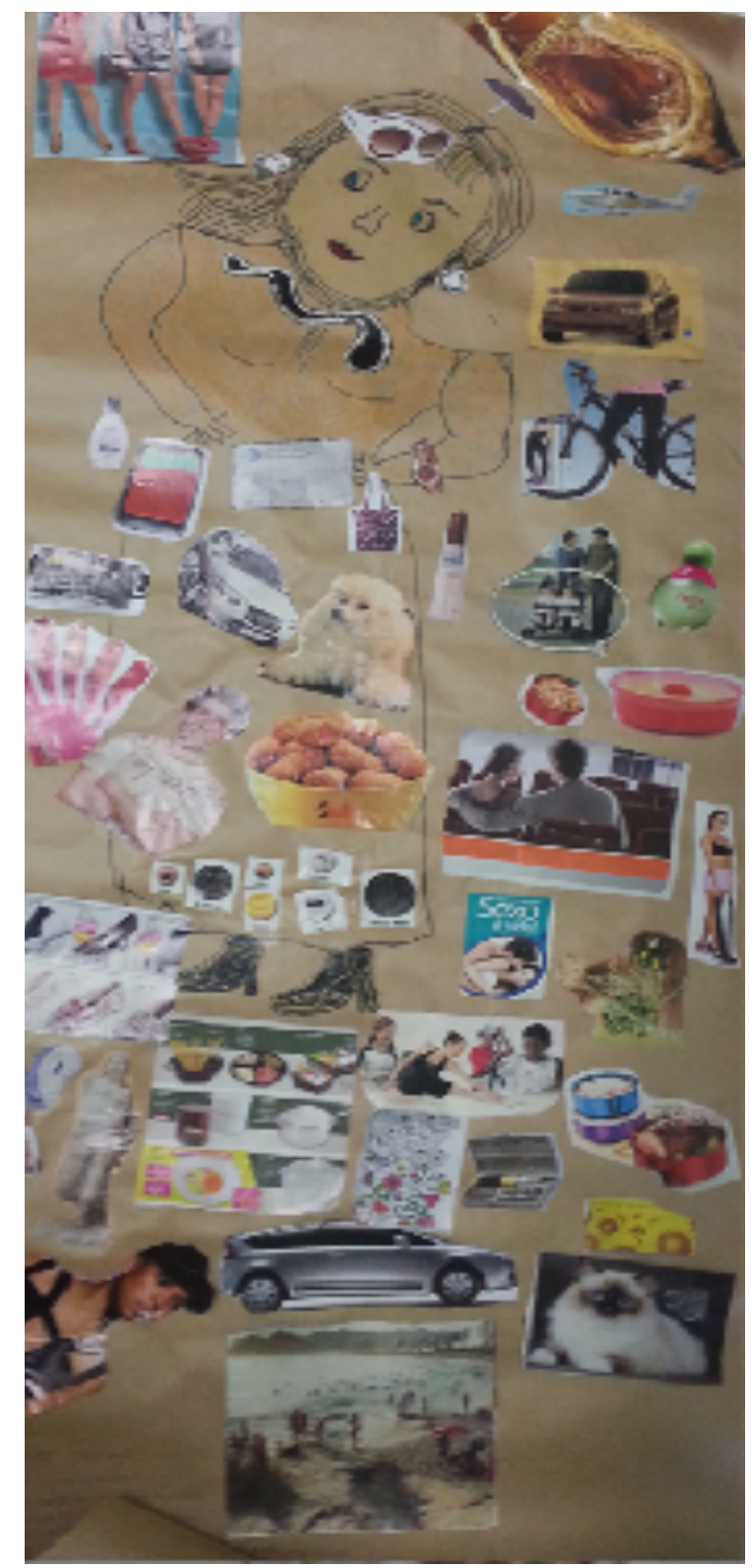

Figura 2. A mulher que supera a si mesma. Colagem. 2016. Acervo da autora.

\section{CONCLUSÕES PARCIAIS}

Sabe-se que o período mais longo,do desenvolvimento humano, que as pessoas percorrem a fase adulta e, a imagem corporal adquirida durante este período tende a acompanhar a pessoa até o envelhecimento. Este fato persiste até o momento em que 
o outro vê o idoso, como idoso. Ouve-se em suas falas:"eu não sou velho, os outros é que acham". Assim, percebe-se que nem sempre mente acompanha a faixa etária, e que esta é uma construção social. A compreensão do próprio envelhecimento não passa necessariamente por uma linha temporal, pois há dias em que o idoso se sente jovem e, em outros, se sente além de sua idade.

Durante as atividades desenvolvidas nas Oficinas de criatividade, do projeto Laços de vida, percebemos, no decorrer dos depoimentos, a possibilidade da imagem corporal nem sempre coincidir com a etapa cronológica de vida esperada.

A arte como recurso expressivo neste estudo, trouxe uma contribuição relevante, de forma a propiciar, através da pintura, da colagem e do desenho, uma fala simbólica relativa as situações de vida das participantes, como na criação de histórias e personagens, para que pudessem projetar suas próprias histórias.

Observamos, também, que conflitos, perdas e problemas de saúde, terminam por confrontar o idoso com seu corpo real, mas também constatamos que os bons momentos relatados, faziam com que as participantes se sentissem rejuvenescidas. Mucida (2004) discute a ideia de que, apesar dos registros do tempo, o desejo não envelhece, o que nos leva a pensar que esse, quando bem vivido e orientado durante as etapas de vida, pode gerar uma velhice mais bem resolvida e positiva.

Pensamos que as atividades desenvolvidas, junto ao grupo de mulheres, do CRM na cidade de Ivoti, trouxeram uma melhoria para sua autoestima e para as vicissitudes do envelhecimento. Mesmo que exista a velhice, essa precisa ser pensada no contexto onde se insere. As imposições que o envelhecimento imprime, estão sendo cada vez mais relativizadas ante os parâmetros estabelecidos, devido às narrativas culturais de diversos saberes, mas a resposta será na forma de cada um. Esperamos que estas reflexões possam incentivar abordagens relativas à nossa temática, como também no aprimoramento de futuras pesquisas. 


\section{EDUCAÇÃO, \\ ARTES E INCLUSÃO}

\section{REFERÊNCIAS}

ANDRADE, L. Q. Terapias Expressivas. São Paulo: Vetor, 2000.

BALBINOTTI, Helena Beatriz. Finimundi - Adulto Maduro: o pulsar da vida. Porto Alegre: WS Editores, 2003.

BLESSMANN, E. J. Corporeidade e Envelhecimento: o significado do corpo na velhice.Estud. interdiscip. envelhec., Porto Alegre, v. 6, p. 21-39, 2004.

BRASIL. Portaria $n^{\circ} 2.528$. Política Nacional de Saúde da Pessoa Idosa. Disponível em:< http://bvsms.saude.gov.br/bvs/saudelegis/gm/2006/prt2528_19_10_2006.html. Acesso em:> mar.2020.

MONTEIRO, P. P. Envelhecer: histórias, encontros, transformações. Belo Horizonte: Autêntica, 2001.

MUCIDA, Ângela. O sujeito não envelhece: Psicanálise e velhice. São Paulo: Autêntica, 2004.

PAIN, Sara. Os Fundamentos da Arterapia. Petrópolis: Vozes, 2009.

Projeto de Extensão: Laços de Vida - bem-estar de mulheres em situação de

vulnerabilidade.Líder: RonalisaTorman. PROPPEX, Universidade Feevale, 2016/2017.

Recebido em 23 de maio de 2019 Aprovado em 27 de março de 2020 